\title{
Youth Exposure to Violence in an Urban Setting
}

\author{
David Seal, ${ }^{1}$ Annie Nguyen, ${ }^{2}$ and Kirsten Beyer $^{3}$ \\ ${ }^{1}$ Global Community Health and Behavioral Sciences, Tulane University School of Public Health and Tropical Medicine, \\ 1440 Canal Street, Tidewater 2301, New Orleans, LA 70112, USA \\ ${ }^{2}$ Department of Family Medicine, Keck School of Medicine at the University of Southern California, 1000 S. Fremont Avenue, \\ Unit 22, Alhambra, CA 91803, USA \\ ${ }^{3}$ Institute for Health and Society, Medical College of Wisconsin, 8701 Watertown Plank Road, Milwaukee, WI 53226, USA \\ Correspondence should be addressed to David Seal; dseal@tulane.edu
}

Received 10 June 2014; Revised 3 October 2014; Accepted 15 October 2014; Published 10 November 2014

Academic Editor: Enda Murphy

Copyright (C) 2014 David Seal et al. This is an open access article distributed under the Creative Commons Attribution License, which permits unrestricted use, distribution, and reproduction in any medium, provided the original work is properly cited.

\begin{abstract}
To inform a city-wide youth Violence Prevention Initiative, we explored youth narratives about their exposure to violence to gain insight into their understanding of the causes and effects of violence in their communities. At-risk youth were recruited through street outreach for individual interviews and focus group sessions. Types of experiential violence identified included (1) street, (2) family/interpersonal, (3) school, (4) indirect exposure (e.g., neighborhood crime), and (5) prejudice/discrimination. Reactions ranged from motivating positive effects (resilience, determination to escape) to negative effects (fear, paranoia, and aggression). For some, experiences with violence motivated them to pursue educational achievement and positive lifestyles. Causes of violence were described by participants as existing at a number of different levels (societal, neighborhood, interpersonal, and individual), reflecting a social-ecological perspective. Our findings highlight a need for violence prevention efforts that focus on a broad definition of violence, as well as on the poly-victimization of children and youth. At the same time, our findings highlight the challenges of conducting effective community-based prevention programs in urban settings characterized by spatial inequalities and social exclusion of community residents.
\end{abstract}

\section{Introduction}

Injury and violence prevention are recognized as public health priorities in Healthy People 2020 [1] and by the Centers for Disease Control and Prevention [2]. Violence is pervasive and costly to society and causes considerable years of potential life lost. Youth violence, in particular, is a significant problem. According to the CDC, homicide is the second leading cause of death for youth and young adults aged 15-24 years and the leading cause of death among minority youth [3]. Youth living in inner city neighborhoods are at increased risk for exposure to violence. It is estimated that between 50 and $96 \%$ of urban youth have witnessed or experienced some form of violence in their community [4]. In the National Survey of Children's Exposure to Violence [5], $60 \%$ of youth reported experiencing or witnessing violence in the past year. Over $85 \%$ of respondents who had experienced lifetime violence had experienced or witnessed violence within the past year, while slightly over a third of participants had experienced or witnessed multiple forms of violence in the past year.

Exposure to violence during childhood and adolescence, in terms of both direct victimization and secondary exposures such as witnessing violent acts, puts youth at increased risk for a number of adverse health and behavioral outcomes. These adverse outcomes include depression, anxiety, and posttraumatic stress disorder [6,7], aggressive behavior $[8,9]$, suicide ideation [10], and declines in school achievements and high school completion [11, 12]. Violence victimization can also lead to feelings of despondency about having a happy or long life and feelings of being uncared for or unloved [13].

Given the severity and gamut of adverse outcomes associated with exposure to violence, primary prevention efforts to reduce youth exposure are a public health priority. Researchers and practitioners are becoming increasingly 
aware that prevention strategies need to start with the identification of root causes [14]. However, the causes and factors related to violence exposure are complex and multifaceted. The early work of Dahlberg [15] drew upon Bronfenbrenner's [16] ecological systems theory and identified four levels of influence to explain the risk factors that increase the probability of exposure to violence: (1) individual, (2) family, (3) peer and school, and (4) environmental factors. Other scientific theories link neighborhood conditions to the occurrence and frequency of violent crimes and crime rates. Strain theory [17] posits that overall neighborhood disadvantage creates conditions in which residents fail to achieve positively valued goals, lose positive stimuli, and experience negative stimuli leading to increased levels of anger and frustration. The increase in levels of negative emotions is thought to lead to an environment in which crime, particularly violent crime, is more likely to occur [18]. These neighborhood social characteristics influence the ability of residents to maintain social cohesion and informal social control, known broadly as collective efficacy [19]. Research has shown that collective efficacy is associated with fewer variations in violence, while social control, cohesion, and trust are predictors of lower rates of violence [19]. Neighborhood disorder and the "broken windows" theory of urban decline [20] hypothesize that things such as graffiti, garbage, and abandoned cars provide criminals with the visual cues that alert them to neighborhoods in which residents are assumed to be indifferent about what occurs around them, thus promoting crime [21].

Violence exposure has been studied on the neighborhood level and approaches to violence prevention are increasingly being addressed and implemented at the community level through community mobilization and youth empowerment methods [22-24]. For example, Yonas et al. [25] conducted interviews with prominent neighborhood individuals to examine the local dynamics of violence within communities and gain insight to existing yet overlooked neighborhood capacity for collaboration with law enforcement and other agencies. They found subtle differences in existing capacities between low- and high-risk neighborhoods. Individuals from high-risk neighborhoods were less likely to be engaged in neighborhood-level prevention efforts and more likely to view calling the police as a futile effort. Other studies have examined risk factors for violence at multiple levels of influence $[4,26,27]$. Nonetheless, researchers have called for more investigation on disentangling the effects of neighborhood factors from individual factors on the risk of secondary exposure to violence $[28,29]$.

Research shows that neighborhood contexts can contribute to youth risk of exposure to violence. Those living in more disadvantaged environments witness violence at higher rates than those living in less disadvantaged environments [29], which in turn leads to increased risk for adverse outcomes. However, much remains unknown about the mechanisms by which neighborhood contexts affect individual risk, and more research is needed to understand the intricacies of this causal pathway and how to develop effective interventions that interrupt these pathways and reduce risk. Studies that explore the ways in which community-level factors impact individual behavior may also inform understanding of the ways in which community characteristics mediate the effects of individual characteristics [30]. Youth perspectives can generate insight into neighborhood contexts from an insider point-of-view.

In this paper, we summarize youth narratives about their day-to-day exposure to violence in order to gain insight into their understanding of the causes of violence in their communities and the effects of violence on their well-being. These data were collected as part of an in-depth 18-month community needs assessment to develop a call for applications from community partnerships to develop, implement, and evaluate youth violence prevention program (see [31] for complete needs assessment report). The needs assessment assimilated data from multiple sources, including diverse community stakeholders, at-risk youth, neighborhood indicator data (e.g., poverty and crime levels), and relevant community reports and empirical literature. Findings from this needs assessment study informed the development of multiple neighborhood-based youth violence prevention programs based on a social-ecological model of risk.

\section{Methods}

2.1. Study Setting. Participants were recruited from several zip codes characterized by high rates of fatal and nonfatal violence in Milwaukee, a Midwestern town in the United States of about 600,000 people. In 2011, roughly $42 \%$ of homicide victims in Milwaukee were 25 years old or younger and homicides involving victims aged 17 years and younger increased by $57 \%$ from the previous year. Eighty-one percent of victims aged 25 years or younger were Black [32]. The Youth Risk Behavior Surveillance indicated that, in Milwaukee, $22 \%$ of high school males reported carrying a weapon, $41 \%$ of all high students had been in a physical fight in the prior 12 months, and $13 \%$ of all high school students had experienced some form of dating violence [33]. In 2010, over 2,500 young people under 25 years old in Milwaukee were treated in an emergency department or hospitalized for a violence-related injury, with treatment costs reaching nearly 10 million dollars (c.f. [34]).

Further, Milwaukee is characterized by historical and enduring racial and ethnic inequalities and socioeconomic disparities that consistently rank at the top of large U.S. cities [35]. The city has been ranked among the top 5 most racially segregated cities in the U.S. for over 60 years. Based on 2010 census data, Frey [36] reported that Milwaukee had the highest rate of segregation between African Americans and Whites among over 100 of the largest metropolitan regions in the U.S. and 9th highest in comparison of White nonHispanics and Hispanics. Similarly, Milwaukee ranked 2nd and 8th, respectively, for school segregation in comparison of White versus African-American and Hispanic youth (c.f., [35]). Large disparities also exist for poverty rates, residency in neighborhoods with extreme concentrated poverty $(>40 \%$ rate), home loan denial rates, school test performance success, educational achievement, employment rates, minority business ownership, arrest and incarceration, and criminal sentencing disparities (c.f., [35]). 
2.2. Procedures. Individual semistructured interviews using a standardized script were conducted with 18 young adults, aged 18-25 years, living in zip codes with high rates of violence. Interview participants were purposively recruited for their knowledge of gangs and street violence in Milwaukee through street outreach by the project manager, who had 25 years of experience working with street gangs and other high risk youth. Interviews were conducted by the project manager and lasted between 45 and 60 minutes. All interviews were audiotaped and transcribed.

In addition to the individual interviews, we conducted focus groups to include younger participants and to gather a greater number of youth perspectives. Eight 60- to 90-minute focus group sessions using the same set of questions were conducted with 64 young people, aged 14-25 years. Focus group participants were recruited through local community agencies that provided services to at-risk youth in these same zip codes. Focus groups were cofacilitated by the lead author and the project manager and all were audiotaped and transcribed. Snacks were provided to participants at all sessions. No other incentives were provided.

All participants also completed a brief demographic survey assessing gender, age, race/ethnicity, and level of education and a checklist summary to assess the types of violence they had personally experienced and/or witnessed. Items for the checklist summary were developed through discussion with front-line staff and community advisors who were involved in youth violence prevention work.

All study protocols and materials were approved by the Medical College of Wisconsin's Institutional Review Board. Informed consent or assent was obtained from all participants. Parental consent was obtained for participants under the age of 18 years.

2.3. Data Analyses. Transcribed interviews and focus groups were analyzed for emergent themes using content analysis guided by the principles of Grounded Theory [37, 38]. We initially examined the transcripts to identify primary coding categories as well as the range of themes present within each category. Identified coding categories and themes were organized into a formal codebook, and illustrative quotes relevant to these themes were extracted from the transcripts. Next, transcripts were content coded. The coding team discussed new themes that did not appear to fit into the original codebook and modifications were made when deemed appropriate. When suggested by associations, overlap, or diversions in the data, thematic categories were refined, merged, or subdivided. Two members of the analytic team rated all data. Interrater discrepancies were discussed until consensus about the appropriate code was obtained. Decision trails were noted and documented to assure that interpretations were supported by the data $[39,40]$.

\section{Results}

3.1. Participants. Individual interview participants included 12 males and 6 females. Ages ranged from 18 to 25 years with a mean age of 21.6 years. The interview sample was diverse
TABLE 1: Summary of participants responses from the violence experience checklist, youth ages 14-25 years.

\begin{tabular}{lccc}
\hline Violent offense & $\begin{array}{c}\text { Number of participants who } \\
\text { witnessed or experienced } \\
\text { form of violence } \\
\text { Interviews } \\
(n=18)\end{array}$ & $\begin{array}{c}\text { Tocus groups } \\
(n=64)\end{array}$ & $\begin{array}{c}\text { percent } \\
(N=82)\end{array}$ \\
\hline $\begin{array}{l}\text { Beating someone up } \\
\text { Harassment or teasing }\end{array}$ & 18 & 61 & $96.3 \%$ \\
$\begin{array}{l}\text { Bullying } \\
\begin{array}{l}\text { Discrimination or } \\
\text { prejudice }\end{array}\end{array}$ & 18 & 59 & $93.9 \%$ \\
$\begin{array}{l}\text { Mental or emotional } \\
\text { abuse }\end{array}$ & 17 & 59 & $93.9 \%$ \\
$\begin{array}{l}\text { Gun violence } \\
\text { Violence with a weapon }\end{array}$ & 15 & 53 & $85.4 \%$ \\
that is not a gun (e.g., a & 13 & 49 & $80.5 \%$ \\
knife or chain) & & 49 & $78.0 \%$ \\
$\begin{array}{l}\text { Physical abuse } \\
\text { Child abuse }\end{array}$ & 17 & 48 & $74.4 \%$ \\
$\begin{array}{l}\text { Being shot or seeing } \\
\text { someone get shot }\end{array}$ & 12 & 40 & $69.5 \%$ \\
$\begin{array}{l}\text { Partner abuse } \\
\text { Sexual abuse }\end{array}$ & 12 & 43 & $67.1 \%$ \\
Rape or forced sex & 9 & 42 & $65.9 \%$ \\
\hline
\end{tabular}

with respect to race/ethnicity. Participants were identified as African-American $(n=8)$, Latino $(n=7)$, Caucasian $(n=2)$, and Native American $(n=1)$. Seventy-two percent of participants had at least a high school degree. Focus group participants included 35 males and 29 females. Ages ranged from 14 to 25 years with an overall mean age of 16.8 years. The mean age for males was 16.3 years and 17.4 years for females. The majority of focus group participants were identified as African-American (87.5\%) with others identifying as Latino, Caucasian, or Native American. Level of education completed ranged from eighth grade to college graduate with a mean of 10.6 years of education completed. All participants lived in target neighborhoods identified for inclusion in the subsequent prevention program phase of the study.

3.2. Violence Experience Checklist. The checklist summary indicated that all youth in the study reported seeing or experiencing multiple forms of violence. On average, youth had seen or experienced 9.3 items out of the 13 items assessed (see Table 1). The three most commonly witnessed or experienced offenses, as indicated by more than $90 \%$ of all participants, were harassment or teasing, bullying, and beating someone up. Over $70 \%$ of participants had seen or experienced some form of discrimination or prejudice, mental or emotional abuse, violence with a weapon that is not a gun, and gun violence. Child abuse, partner abuse, physical abuse, and being shot or seeing someone get shot were seen or experienced by over $60 \%$ of participants. Finally, 
the two least commonly witnessed or experienced offenses were sexual abuse (43\%) and rape (28\%).

\subsection{Key Themes from Individual Interviews and Focus Groups}

3.3.1. Types of Violence Experienced. Participants were asked to describe the types of violence they experienced or witnessed in their neighborhoods. Types of violence experienced or witnessed by youth, included (1) random and intentional incidents on the street, (2) family/interpersonal, (3) school, (4) indirect exposure (e.g., neighborhood crime), and (5) prejudice/discrimination.

Random and intentional incidents on the street included being a part of, or witnessing, acts of homicide or other types of physical violence. These types of incidents often were said to be related to gang or territorial conflicts. Exposure to gang activity was common and many youth reported being in a gang at an early age or knowing someone who was in a gang:

"Everybody around me were gang bangers. I always had to fight for myself... I was never affiliated with a certain gang but I hung out with a lot of people that were in gangs... I've seen a lot of friends get killed, innocent people too, cousins getting shot, having to witness my cousins getting shot. A real good friend of mine-she was shot and killed. Her boyfriend was a gang member. She was shot and killed because of him."

Respondents also reported various forms of family violence, including domestic or child abuse, physical violence, and verbal abuse perpetrated on family members. Interpersonal violence involved dimensions of sexual violence, such as assault and rape, as well as controlling or manipulative relationships. One example frequently mentioned was the abuse that arose from relationships between younger females and older males:

"There are these young girls, 13, 14, who go with the guy around 18, 19. They like the guy so much, he feels the need to control her, and like, she doesn't do something right, or she does something wrong, he abuses her."

Bullying, put-downs, teasing, arguments and fights over boys, cliques clashing, and school fights were reported in the school environment. Some female respondents reported that fighting over boys led to acts of retaliation, such as the spreading of rumors which can escalate to physical fights. The concept of clique conflicts being antecedent to violent acts was a prevalent one. Having the "backup" of a clique or group of friends gave some people the ability to bully others:

"When I used to be in school, I used to be a bully, little as I was. But the thing about that was I had a lot of backup behind me, so the things I did or who I did it to-they was kind of scared, because they deal with me, they had to deal with half the school."

Indirect violence involved incidents that threatened youth's sense of safety and overall well-being. These included acts that youth knew to be pervasive in their neighborhood environment but which were not necessarily directed toward youth. Consistent with what Wilson and Kelling [20] termed "neighborhood disorder," examples of these acts included the frequent occurrence of robberies and burglaries, drug dealing, prostitution, vandalism, and observed police brutality in the neighborhoods in which youth lived. Though acts of indirect violence were prevalent in their neighborhoods, participants revealed a belief that not all acts of violence committed in their neighborhoods were perpetrated by residents. For example, one individual spoke of nonresidents who came into the neighborhood to obtain drugs:

"When I was talking about the guy who had overdosed, he was actually from the suburbs and he had come into the 'hood' to get some drugs and he parked in order to administer the drugs to himself and that's when he overdosed right there in front of my house."

Consistent with Sampson and Raudenbush's [21] concept of "seeing disorder," some youth said that the news media perpetuated stereotypes about their neighborhoods by choosing to report on violence that occurred in their neighborhoods and not others. Other respondents felt that violence and crime in upper-class neighborhoods were "covered up" by the media creating an unfairly heightened sense of danger toward their own neighborhoods.

Prejudice and discrimination were identified by youth as a form of violence that included hate acts based on religion, race and ethnicity, and sexual orientation. One participant explained the tension that existed between young people of different races:

"Where I'm from... there's not too many Black folks around there and I was in [high school A] my first year of high school. And I remember in [high school A] the Black kids that went to [high school $A]$, they had to get escorted off the bus to the school and then from the school back to the bus stop after school just so they wouldn't get jumped on. That's still to this day. That's still racial discrimination. That brings upon so much violence. Black people don't want to see White guys, Hispanic guys with their Black girls and vice versa."

3.3.2. Youth Reactions to Violence. Respondents were asked to describe the ways in which their personal lives have been affected by violence. Reactions ranged from expressions of negative affect to displays of resiliency. Negative psychological and emotional effects included feelings of fear, a general sense of being in danger, and paranoia. These feelings were exhibited through avoidant behaviors and hyperawareness of surroundings. Many youth stated that they avoided being out late or alone, kept to themselves in order to reduce the likelihood of encountering a violent situation, and took care to avoid wearing clothing that may be misconstrued as gangaffiliated gear. Other youth expressed feelings of anger, hurt, guilt, and difficulty with coping. Some reported a diminished sense of trust toward others which impeded development 
TABLE 2: Key themes organized in a socioecological framework of underlying causes of violence.

\begin{tabular}{ll}
\hline \multirow{2}{*}{ Individual influences } & $\begin{array}{l}\text { Feelings of anger, fear, rage, resentment, and frustration } \\
\text { Feelings of hopelessness, as if there is "nothing to live for" } \\
\text { Lack of problem solving, conflict resolution, and communication skills necessary to cope with strong emotions }\end{array}$ \\
\hline & Cycle of violence within and over generations \\
& Homes as unsafe places \\
& Lack of proper parental guidance, boundaries, and supervision \\
Interpersonal influences & Neglect, abandonment, or betrayal within family \\
& Verbal disagreements with peers about disrespect, gossip, or other issues that escalate into violence \\
& Feeling of needing to "fight back" in order to avoid being perceived as weak \\
& Gangs and drug dealers provide "brotherhood" or "acceptance" that cannot be found elsewhere \\
\hline \multirow{2}{*}{ Neighborhood influences } & Social environment affecting perception of what is possible \\
& Lack of resources and programs \\
& Lack of safe places in neighborhood, including schools \\
\hline \multirow{2}{*}{ Societal influences } & Lack of education and jobs and poverty \\
& Economic disadvantage, racial segregation, and justice \\
& Culture of violence as reflected in the media, TV, and music \\
\hline
\end{tabular}

of close friendships. A sense of hopelessness or reduced opportunities for the future was evident in statements such as

"It's like nobody wants to give you a chance because you're from this side... It's always like we have the reputation of just like being this bad side... all this crime, all this violence... they don't give us a chance to tell about the real person we are."

Some participants stated that they had become accustomed to violence and accepted it as a normal part of life. The need for self-protection was cited as a consequence of exposure to violence. Some youth felt the need to arm themselves with weapons such as a gun or pocket knife as a form of defense. This sentiment extended beyond the individual and some reported that their families kept guns in the home in order to protect the family: "So the only way that people in the hood really know to protect themselves from gun violence is to get guns themselves."

In contrast, another category of responses focused on positivity and resilience. Some individuals expressed a strong determination to move beyond violence and to "watch out for each other." These individuals said that exposure to violence allowed them to develop a sense of right from wrong and to learn the consequences of violent actions from seeing it firsthand:

\section{"But it also affected me in a positive way because you know I can say, okay, I know what this is and I know what not to do, I know what not to be a part of. And I know I have an example and it kind of gave me a sense of knowing the consequences of things."}

For some youth, these experiences motivated them to seek a life away from violence by pursuing higher education and career choices, such as becoming a teacher in order to reach out to kids.
3.3.3. Perceived Causes of Violence. Factors associated with violence were described by participants as existing at a number of different levels, supporting a social-ecological perspective (see Table 2).

At a societal level, respondents discussed the relationship between a lack of education and jobs, poverty, and violence. They discussed the pressures of poverty, saying that "people rob and steal because they can't get a job" and that people want "quick money" because they want their "situation to be gone." They also discussed the interrelation of issues such as economic disadvantage, race, segregation, and justice as seen in this quote:

"I think the situation here is just so much more desperate. I mean the fact that [city] is still so segregated. I mean, I think we've just allowed certain races to exist at this level of just... I mean, it's really not fair. It's a desperate situation. They [Black people] don't have the same types of jobs as White people do in general. They don't have the same resources... the same education."

Youth also discussed the role of contemporary culture in encouraging violence. They described a culture of violence that is reflected in the media, television, and music, which can sometimes "glorify" or promote violence and negativity.

Many respondents acknowledged that the social environment at the neighborhood level shaped youth behavior by affecting their perception of what is possible in their lives:

\section{"If you're in an environment where everybody, you know, is negative and there's no, like, light, then I guess you just adapt to it and, you know, you just feel like there's no way for me to be better if nobody else is."}

One aspect of the neighborhood environment that respondents associated with higher likelihood of violence was the real or perceived lack of resources and safe places 
available to youth in the community, including the associated absence of structured time and interesting activities. While some respondents cited the limited resources available, others cited a general lack of awareness of existing programs. Youth programs were described as a possible way of showing youth that they had other options in life, aside from participation in violence:

"I feel that more children should get involved in
programs... Programs are really, I think they're
good. They keep kids like, you know, focused,
you could say. And that's what we need like
educational programs, programs that will take
you out of [city] and experience life somewhere
else like college tours or stuff like that. To see how
it is to live beyond, you know, this scope, open you
up a little bit."

Respondents argued that lack of safe spaces combined with a general deficit in positive role models and effective parenting contributed to negative feelings among youth, including boredom, which lead some youth to turn to negative activities to fill their time. When asked where youth felt "safe," respondents often identified their own home, the homes of trusted family members, or venues and organizations that offer after school programs or activities, such as community organizations, sports leagues, and tutoring and mentoring programs. Other identified "safe" places were churches, malls, and libraries. Others stated that they felt safe anywhere as long as they felt protected, such as being around people with whom they feel comfortable or being with someone who has a gun or another form of self-protection. A large number of individuals stated that there is nowhere to go to feel safe:

"I don't feel there's a lot of places you can go, because everywhere you go, there's violence occurring. Just walking down the block to a friend's house, that's not safe anymore. Parks really aren't safe anymore, especially when it turns night time. The mall's not even safe anymore."

Being out in the streets or neighborhoods was usually perceived as unsafe, especially if it was an area away from one's home or territory. Some youth specifically identified their homes as being "unsafe," citing family violence and other concerns. Schools and specific locations within schools (e.g., the lunchroom) also were often mentioned as unsafe places. Respondents reported that they felt unsafe in schools because students brought weapons to schools and caused fights and riots.

At the interpersonal level, two main clusters emerged: familial and peer. Within the familial cluster, respondents stressed the importance of good parenting and having a strong role model. Youth expressed frustration that there are not enough people "to encourage young people to do better and stay out of trouble." The cycle of violence experienced within many families was discussed, including the strong connection between youth behavior and various forms of family violence, including domestic violence and child abuse:

"Growing up I was physically abused, in my family. My dad was very abusive to my mother, to us. Gang violence, my dad had a lot to do with gang violence. And then he brought my brothers up knowing that, so my brothers even until now know about gang violence, physical abuse, like beating up on females and what not... So as I got older, I used to shell myself or like keep distance from people. I wouldn't let certain people know like my feelings and I used to be real cold... You just learn not to care about people."

More generally, respondents indicated that the nature of life at home involved neglect and a general lack of proper parental guidance, boundaries, and supervision. They attributed this in part to financial instability and the fact that many parents are working two jobs to support their family, leaving them little time to provide nurturance and care to their children. Youth felt this was particularly true for young parents and single-parent homes, especially those without fathers in the home, and noted the lack of parenting skills among adolescent parents:

"It's parents and poverty basically. Because of poverty... some parents have to work on second shift jobs and they're not able to watch their kids. And the other is like I said, like parents are around my age and they ain't raising their kids right. They tell 'em 'go sit down' or 'go play outside', and kids tend to go out the neighborhood with other kids destroying everything. And that's how they have fun."

Respondents discussed the emotional toll of growing up in a negative family environment. Some emphasized the betrayal felt due to abandonment by parents and significant others in their lives:

"I felt like a strong betrayal from my mom and so
anyone who betrays me I feel that same feeling that
my mom, you know, when my mom left me. I felt
that same feeling that I just wanna hurt someone
and I get, you know, angry and angrier."

Within the peer cluster, respondents talked about verbal disagreements that escalated into physical violence. These included responses to being offended or disrespected (greater among males) or in response to gossiping or talking about someone (greater among females). These disagreements often arose from disputes about boyfriends and girlfriends, bullying, teasing/name-calling, the need for retaliation/selfprotection, and the need to defend one's reputation. Respondents described the tendency for small disputes to result in larger scale conflict: "I think probably most of the time it's just little disputes, like arguments... from my experience, it was little things. Little things would set me off and make me mad."

Respondents noted that you can appear "soft" or "weak" if you do not fight back, that peer-pressure/influence (e.g., people thinking it is "cool" to fight) plays a role, and described the existence of a feeling of "competition," that "there can only be one person who's the best." Other interpersonal factors perceived to underlie violence included a lack of tolerance for diversity, pride, and jealousy: "I want what you have." 
They further noted that some kids became involved with gangs and drug dealers to seek "brotherhood" or "acceptance" that they cannot find elsewhere, particularly at home. Gangs were described as providing safety, group identification, and acceptance, as well as being a mechanism to obtain money and prestige (e.g., cars, women):

\begin{abstract}
"There is that sense of family in a gang. I'm there for you 24/7. Just call me. If you have problems at home, come to my house. My house is your house. My clothes is your clothes. Whatever I have is there for you $24 / 7 . .$. I don't have any other options. I go home, my mom is going to beat me. There is no food at home for me to eat. When I'm in a gang, I have a job. I'm employed 24/7. I work on the corner. I sell drugs. I make money. I have a car. I have a gun. I have drugs. I have girls. Girls come to me. I don't go to girls. I feel safe. I feel safe with a gun. I feel safe with my gang that I run with."
\end{abstract}

Yet, paradoxically, gang involvement also was described as increasing risk of violence, as the requirements of being in a gang may include perpetrating violent acts: "But there is a relapse. I'm there for you 24/7. You have to be there for me 24/7. That is where the problem comes in with a gang."

At an individual level, respondents talked about feelings of hopelessness, anger, fear, rage, resentment, and frustration. They attributed these feelings to the pervasiveness of violence and other negative influences in their lives, including parental neglect and abuse. They noted that "having had it bad in life" can make one feel like there is "nothing to live for," which in turn affects behavior. Respondents said that many youth lacked the necessary problem solving, conflict resolution, and communication skills to cope with these negative emotions. Instead, many youth turn to substance abuse or lash out at others: "Anytime someone looked at me wrong I felt like I wanna hit them and it's just a trained thought that just comes into your head."

They discussed the fact that sometimes these negative emotions, combined with lack of coping skills, lead youth to commit "random" acts of violence, that they "do it just to do $i t$ " or because they were having a bad day or were feeling bored, sometimes choosing to act upon a random person instead of a family member.

\section{Discussion}

Kilroy [41] posited that "spatial inequalities within urban areas are a natural consequence of income inequalities between households" (page 3), which results in clusters of economically disadvantaged neighborhoods in central cities. Further, these neighborhoods are often predominantly inhabited by racial and ethnic minorities. As work force opportunities move away from central cities to suburban markets, inhabitants in these neighborhoods face reductions in labor market opportunities. They also lose the benefit of local economic growth, which in turn reduces social and political power. Collectively, these factors result in "social exclusion" [42]. Aspects of social exclusion include exploitation, marginalization, and deprivation. Culturally, social exclusion includes injustices related to social values, devaluation of cultural mores, and racist or discriminatory policies and actions. Ultimately, this leads to reduced access to resources and social status and respect.

Youth participants in our study reflected on spatial inequalities in their neighborhood environments (e.g., pervasive of crime, lack of educational and employment opportunities, and lack of youth activity sources). Findings from youth also were consistent with what Sampson and Raudenbush [21] refer to as "seeing disorder." The concept of seeing disorder suggests that implicit biases influence the ways in which people perceive the disorder of a neighborhood, including visual cues of disorder (e.g., vandalism, the presence of drug paraphernalia, and graffiti) that attract criminals and crime [20]. These authors posit that these negative visual cues draw criminals to neighborhoods in which residents are assumed to be indifferent about what occurs around them, thus promoting crime [21].

Participant perceptions of neighborhood disorder were reflected in their description of the pervasiveness of violence in their everyday lives in the impoverished inner city areas in which they lived. These experiences of violence included random street violence, family and interpersonal violence, school and peer-based violence, indirect forms of violence, and prejudice or discrimination. The concept of seeing disorder is further reflected in youth's belief that the news media perpetuates stereotypes of violence in their neighborhoods by choosing to report on crime and violent acts in their neighborhoods and not others. Collectively, these perceptions are consistent with strain theory [17] which posits that overall neighborhood disadvantage creates conditions in which residents fail to achieve positively valued goals, lose positive stimuli, and experience negative stimuli leading to increased levels of anger and frustration. The increase in levels of negative emotions is thought to lead to an environment in which crime, particularly violent crime, is more likely to occur [18].

Indeed, youth in our study articulated the connection between inequalities in their spatial and economic environment (e.g., racial segregation, lack of educational and employment opportunities) and involvement with crime and gangs. Youth in our study further asserted that many residents in their communities turned to crime in order to survive, a connection documented by Hagedorn [43]. In his analysis of inner-city neighborhoods in Milwaukee, Hagedorn concluded that drug dealing is an "innovative, entrepreneurial, small business venture" that fills a small business void through resident "employment." In another article, Hagedorn [44] asserted that the drug business was the leading employer of young African-American men in their operating neighborhoods, serving a largely White, suburban clientele.

These findings suggest that youth are savvy about their environment and can offer salient explanations for violence in their neighborhood. This demonstrates the value of including youth perspectives and participation in conducting community-based research on youth violence prevention.

Findings from the checklist suggested that youth in our study were simultaneously exposed to multiple forms of 
violence, through either primary or secondary exposure. This finding likely reflects our purposive sampling strategy which aimed to recruit youth associated with gangs and violence through street outreach, as well as recruitment of youth from agencies serving at-risk youth in our target neighborhoods. Yet, our incidence of poly-victimization is not inconsistent with national survey data. In the National Survey of Children's Exposure to Violence [5], over 85\% of respondents who had experienced lifetime violence had experienced or witnessed violence within the past year, while slightly over a third of participants had experienced or witnesses multiple forms of violence in the past year. These authors further found that poly-victimized children experienced an increase in trauma symptoms, including anger, depression, and anxiety over the same time period, emotions often expressed by our study participants.

Collectively, the pervasiveness of violence, coupled with the lack of safe spaces, caused many youth to become isolated and avoidant of their communities. Others became accustomed and indifferent to the threats of violence or become perpetrators of violence for self-protection and/or personal gain. The reported negative psychological and emotional effects of exposure to violence are consistent with the literature $[6,13,45,46]$. The negative psychological effects of exposure to violence further lead some youth to develop a sense of need to carry weapons for self-protection.

However, not all youth reported negative consequences. Some youth reported developing a sense of resiliency and vision for the future in order to seek a life away from violence as a consequence of learning right from wrong. Certain developmental assets can promote positive youth development but few studies have examined the role of violent exposure in developing youth resilience [47]. Data from the Project on Human Development in Chicago Neighborhoods [47] found family boundaries and strong family, peer, and neighborhood support to be associated with reduced aggression and delinquency for all youth, including children exposed to violence. The concept of positive deviance has been used in public health practice to describe the individuals who thrive in low-resource communities because they engage in locally uncommon but health-promoting practices and behaviors. The positive deviance approach attempts to identify these uncommon practices along with ways to promote them to other members of the community. As Walker et al. [48] point out, this approach leads to sustainable and culturally relevant solutions because the starting point is with the discovery of local solutions using existing resources. A positive deviance approach to developing positive assets in youth exposed to violence might start with the identification of the characteristics and motivations of youth who thrive in at-risk environments, as well as existing family and neighborhood resources that can be highlighted to promote positive development. This is an area for further research.

Limitations of this study included its specific regional focus and use of a convenience sample. Thus, study findings may not generalize to communities and populations outside of the region. Furthermore, recruitment was targeted toward high-risk youth which may account for the high frequency of participant reported experiences of violence. However, because this population is the targeted beneficiary and recipient of the current community-based violence prevention intervention (briefly described below), our sample was relevant and appropriate to study goals.

4.1. Program Implications. Findings from this study, along with interview and community forum data from diverse stakeholders (see [31] for complete needs assessment report), were used to inform the development of a city-wide Youth Violence Prevention Initiative (VPI). Specific program recommendations, based on stakeholder data, were identified at all levels of the socioecological framework: individual, interpersonal, neighborhood and community, and societal levels.

At an individual level, core recommendations were (1) provision of structured nurturance and leisure time; (2) promotion of youth assets; (3) promotion of youth leadership and capacity; (4) promotion of coping skills; and (5) provision of structured growth opportunities. At an interpersonal level, core recommendations were (1) development of youth leadership skills and training opportunities; and (2) integration of older and nurturing role-models (e.g., parents, extended families, and adult neighborhood leaders) into youth leadership programs. At the neighborhood and community level, core recommendations were to (1) foster community engagement, cohesion, and empowerment to view violence as a public health issues that is everyone's responsibility to reduce; (2) promote diverse representation in the implementation program process; (3) enlist governmental, systemic, provider, and social service agencies to disseminate common messages related to promotion of social norms, shared values, and behavioral practices related to youth asset development and violence reduction; (4) reduce environmental conditions that impede positive youth asset development; and (5) increase availability of, and access to, needed services. Finally, at the societal level, core recommendations focused on development of capacity and sustainability of youth violence prevention programs (1) advocacy; (2) policy change; (3) resource and service coordination and collaboration; (4) promotion of external funding and resource acquisition; and (5) capacity building and technical assistance.

A workgroup comprised of 10 community leaders, including youth representatives, and 5 academic partners transformed the data collected from youth and other community stakeholders into a comprehensive youth violence reduction plan that included recommendations related to (1) primary prevention for youth aged $0-11$; (2) leadership and capacity development for youth aged 12-17; and (3) mobilizing communities and government to address violence as a public health issue. Four community partnerships were awarded grant funding to conduct rigorously evaluated youth violence prevention programs based on an ecological model. A key requirement was that applicant teams had to be comprised of multiple agencies to offer programming that was synergistically greater than what any of the agencies could do individually. Applicants also had to offer detailed plans to incorporate youth and other community stakeholders into their project planning and leadership. Most applicants 
included youth involvement in their proposal development. Core elements of all funded applicants included programming aimed at the following.

(1) Promotion of positive youth development and problem-solving skills for children aged 0-11 years, including parental skills training. This included working to establish bridges between families, schools, and communities to provide a consistent platform of youth care and service.

(2) Development of leadership capacity and educational attainment among youth 12-17 years of age. Youth Leadership Councils were formed to develop forums for youth to contribute to the conceptual development of VPI program goals and activities, to become advocates for violence reduction in their communities for social and political change, and to create opportunities for community service. This program goal included training and opportunities to promote youth entrepreneurship (e.g., internships in local businesses, employment as program staff for VPI programs).

(3) Education and mobilization of local capacity in support of the programs from neighborhoods, schools, and the broader community. This aim included regular community forums to discuss community concerns and elicit their recommendations about how to address community concerns, conduct of capacity building and cultural competency training for providers in the target neighborhoods, technical assistance for community partnerships with grant applications to increase long-term sustainability of their programs, and working with city government and law enforcement to better understand violence as a public health problem requiring effective public health solutions. The project also worked with community stakeholders to develop policy and advocacy papers related to youth violence prevention. One funded agency partnered with law enforcement to expand positive community policing efforts, reduce abatement, and create community prosecution forums to increase use of local diversion programs in lieu of incarceration for people with minor offenses.

While not described in detail in this paper, core elements of all funded programs were purposively broad so as to allow specific funded groups and their community stakeholders and participants define the best way to develop and implement these elements. Part of the evaluation process is detailed process analyses of program delivery and outcomes, including data at the neighborhood, systemic change, and policy level.

Although the resultant prevention programs aimed to educate and mobilize local capacity in support of the programs, these efforts are still embedded within a setting of spatial inequality and social exclusion. Priority needs identified by youth at a structural level, such as lack of education and employment opportunities, were beyond the capacity of the VPI project. While VPI serves to advocate for increased opportunity, it will require commitment from government and business to address this need. Sampson and Raudenbush [21] point out that many inner-city neighborhoods are stigmatized by historical and structural problems that have deep roots in American social stratification and which are not amenable to short-term intervention. Indeed, our study setting is characterized by historical and structural inequalities that are likely to impact the overall effectiveness of prevention programs embedded within this social context of spatial inequality.

Nonetheless, it is hoped that through promotion of public awareness as a public health issue reflecting social and economic inequalities, policy and advocacy efforts to promote educational and employment opportunities, and mobilization of diverse stakeholder groups, the resultant VPI prevention program will catalyze efforts to address these underlying disparities within governmental and business sectors.

VPI funding provided an opportunity for several youth serving community-based organizations, local businesses, and law enforcement to collaborate. This partnership led to the reopening of a youth center, initially founded in 1989, by neighborhood residents, law enforcement representatives, and business owners that were concerned about youth crime and gang violence. The Center reopened in 2011 after three years of closure due to lack of funding. The inclusion of diverse stakeholders strengthened the operational design. Programming is consistent with the core recommendations and includes youth leadership development, tutoring, arts based education, and parenting support networks. Collaborative efforts to unite youth and families are grounded in approaching violence prevention as a critical public health issue.

\section{Conflict of Interests}

The authors declare that there is no conflict of interests regarding the publication of this paper.

\section{Acknowledgments}

The authors thank the following members of the VPI Community Asset Team for their assistance on this project: Sarah DiPadova, Jose Flores, Pamela (Kohal) Knight, Cheryl Maurana, June Perry, May yer Thao, and Alicia Witten. The Violence Prevention Initiative is a project of the Medical College of Wisconsin Consortium on Public Health funded by the Advancing a Healthier Wisconsin endowment. They also thank Dr. Staci Young for her insightful comments on the paper.

\section{References}

[1] U.S. Department of Health and Human Services, Health People 2020: Understanding and Improving Health, Washington, DC, USA, 2nd edition, 2010.

[2] W. R. Hammond and I. Arias, "Broadening the approach to youth violence prevention through public health," Journal of Prevention and Intervention in the Community, vol. 39, no. 2, pp. 167-175, 2011. 
[3] CDC (2012a), "Facts at a glance: Youth violence," National Center for Injury Prevention and Control, Division of Violence Prevention, 2013, http://www.cdc.gov/violenceprevention/pdf/ yv_datasheet_2012-a.pdf.

[4] G. M. Zimmerman and S. F. Messner, "Individual, family background, and contextual explanations of racial and ethnic disparities in youths' exposure to violence," American Journal of Public Health, vol. 103, no. 3, pp. 435-442, 2013.

[5] D. Finkelhor, H. Turner, R. Ormrod, and S. L. Hamby, "Violence, abuse, and crime exposure in a national sample of children and youth," Pediatrics, vol. 124, no. 5, pp. 1411-1423, 2009.

[6] K. M. Fitzpatrick and J. P. Boldizar, "The prevalence and consequences of exposure to violence among African-American youth," Journal of the American Academy of Child and Adolescent Psychiatry, vol. 32, no. 2, pp. 424-430, 1993.

[7] K. M. Fitzpatrick, D. R. Wright, B. F. Piko, and M. LaGory, "Depressive symptomatology, exposure to violence, and the role of social capital among African American adolescents," American Journal of Orthopsychiatry, vol. 75, no. 2, pp. 262-274, 2005.

[8] D. Gorman-Smith and P. Tolan, "The role of exposure to community violence and developmental problems among inner-city youth," Development and Psychopathology, vol. 10, no. 1, pp. 101116, 1998.

[9] S. F. Lambert, R. C. Boyd, N. L. Cammack, and N. S. Ialongo, "Relationship proximity to victims of witnessed community violence: associations with adolescent internalizing and externalizing behaviors," American Journal of Orthopsychiatry, vol. 82, no. 1, pp. 1-9, 2012.

[10] C. C. O'Leary, D. A. Frank, W. Grant-Knight et al., "Suicidal ideation among urban nine and ten year olds," Journal of Developmental and Behavioral Pediatrics, vol. 27, no. 1, pp. 3339, 2006.

[11] C. C. Bell and E. J. Jenkins, "Traumatic stress and children," Journal of Health Care for the Poor and Underserved, vol. 2, no. 1, pp. 175-186, 1991.

[12] R. Boynton-Jarrett, E. Hair, and B. Zuckerman, "Turbulent times: effects of turbulence and violence exposure in adolescence on high school completion, health risk behavior, and mental health in young adulthood," Social Science and Medicine, vol. 95, pp. 77-86, 2013.

[13] D. E. Howard, S. Feigelman, X. M. Li, S. Cross, and L. Rachuba, "The relationship among violence victimization, witnessing violence, and youth distress," Journal of Adolescent Health, vol. 31, no. 6, pp. 455-462, 2002.

[14] J. Lancaster, "Violence as a public health problem," Family \& Community health, vol. 33, no. 2, p. 79, 2010.

[15] L. L. Dahlberg, "Youth violence in the United States: major trends, risk factors, and prevention approaches," American Journal of Preventive Medicine, vol. 14, no. 4, pp. 259-272, 1998.

[16] U. Bronfenbrenner, The Ecology of Human Development: Experiments by Nature and Design, Harvard University Press, Cambridge, Mass, USA, 1979.

[17] R. Agnew, "A general strain theory of community differences in crime rates," Journal of Research in Crime and Delinquency, vol. 36, no. 2, pp. 123-155, 1999.

[18] B. D. Warner and S. K. Fowler, "Strain and violence: testing a general strain theory model of community violence," Journal of Criminal Justice, vol. 31, no. 6, pp. 511-521, 2003.
[19] R. J. Sampson, S. W. Raudenbush, and F. Earls, "Neighborhoods and violent crime: a multilevel study of collective efficacy," Science, vol. 277, no. 5328, pp. 918-924, 1997.

[20] J. Q. Wilson and G. Kelling, "The police and neighborhood safety: broken windows," The Atlantic Monthly, vol. 127, pp. 2938, 1982.

[21] R. J. Sampson and S. W. Raudenbush, "Seeing disorder: Neighborhood stigma and the social construction of 'broken windows"' Social Psychology Quarterly, vol. 67, no. 4, pp. 319342, 2004.

[22] T. N. Le, I. Arifuku, L. Vuong, G. Tran, D. F. Lustig, and F. Zimring, "Community mobilization and community-based participatory research to prevent youth violence among Asian and immigrant populations," The American Journal of Community Psychology, vol. 48, no. 1-2, pp. 77-88, 2011.

[23] S. S. Leff, D. E. Thomas, N. A. Vaughn et al., "Using communitybased participatory research to develop the PARTNERS youth violence prevention program," Progress in Community Health Partnerships: Research, Education, and Action, vol. 4, no. 3, pp. 207-216, 2010.

[24] M. A. Zimmerman, S. E. Stewart, S. Morrel-Samuels, S. Franzen, and T. M. Reischl, "Youth empowerment solutions for peaceful communities: combining theory and practice in a communitylevel violence prevention curriculum," Health Promotion and Practice, vol. 12, no. 3, pp. 425-439, 2011.

[25] M. A. Yonas, P. O’Campo, J. G. Burke, and A. C. Gielen, "Exploring local perceptions of and responses to urban youth violence," Health Promotion Practice, vol. 11, no. 1, pp. 62-70, 2010.

[26] T. I. Herrenkohl, J. Lee, and J. D. Hawkins, "Risk versus direct protective factors and youth violence: seattle social development project," The American Journal of Preventive Medicine, vol. 43, no. 2, pp. S41-S56, 2012.

[27] R. J. Sampson, J. D. Morenoff, and S. Raudenbush, "Social anatomy of racial and ethnic disparities in violence," American Journal of Public Health, vol. 95, no. 2, pp. 224-232, 2005.

[28] S. L. Buka, T. L. Stichick, I. Birdthistle, and F. J. Earls, "Youth exposure to violence: prevalence, risks, and consequences," American Journal of Orthopsychiatry, vol. 71, no. 3, pp. 298-310, 2001.

[29] C. L. Gibson, S. Z. Morris, and K. M. Beaver, "Secondary exposure to violence during childhood and adolescence: does neighborhood context matter?" Justice Quarterly, vol. 26, no. 1, pp. 30-57, 2009.

[30] S. de Coster, K. Heimer, and S. M. Wittrock, "Neighborhood disadvantage, social capital, street context, and youth violence," The Sociological Quarterly, vol. 47, no. 4, pp. 723-753, 2006.

[31] D. W. Seal, K. Beyer, J. Flores et al., Medical College of Wisconsin Youth Violence Prevention Initiative: Summary Report-Development Phase, 2008-2010, Institute for Health and Society, Medical College of Wisconsin, MCW Consortium on Public and Community Health, Milwaukee, Wis, USA, 2010, http://www.mcw.edu/FileLibrary/Groups/ViolencePreventionInitiative/Reports/VPIReports/VPI.DevelopmentPhaseSummaryReport.Final.20101119.pdf.

[32] Milwaukee Homicide Review Commission, Homicides and Nonfatal Shootings Data Report for Milwaukee, Milwaukee Homicide Review Commission, Milwaukee, Wis, USA, 2012, http://city.milwaukee.gov/ImageLibrary/Groups/cityHRC/reports/2012AnnualReportFinalon7-10-13.pdf.

[33] CDC, "Youth risk behavior surveillance-United States," Morbidity and Mortality Weekly Report, vol. 59, no. SS-5, 2012. 
[34] S. Mishefske and D. J. Peterson, Evidence for Action: A Report on Violence and Health in Milwaukee, MCW Consortium on Health, Medical College of Wisconsin, 2011, http://www.mcw .edu/FileLibrary/Groups/ViolencePreventionInitiative/Reports/ VPIReports/EvidenceforActionReportFinal.pdf.

[35] M. V. Levine, Racial Disparities, Socioeconomic Status, and Racialized Politics in Milwaukee and Wisconsin: An Analysis of Senate Factors Five and Six of the Voting Rights Act, 2012, Expert report submitted on behalf of plaintiffs in Frank v. Walker, Civil Action No. 2:11-cv-01128(LA), https://www.aclu.org/sites/ default/files/assets/2012.05.18_marc_levine_expert_report.pdf.

[36] W. Frey, New Racial Segregation Measures for Large Metropolitan Areas: Analysis of 1990-2010 Decennial Census, University of Michigan Population Studies Center, Institute for Social Research, 2010, http://www.psc.isr.umich.edu/dis/census/segregation2010.html.

[37] J. M. Corbin and A. Strauss, "Grounded theory research: procedures, canons, and evaluative criteria," Qualitative Sociology, vol. 13, no. 1, pp. 3-21, 1990.

[38] A. Strauss and J. Corbin, "Grounded theory methodology," in Handbook of Qualitative Research, N. K. Denzin and Y. Lincoln, Eds., pp. 273-285, Sage, Thousand Oaks, Calif, USA, 1994.

[39] J. M. Hall and P. E. Stevens, "Rigor in feminist research," Advances in Nursing Science, vol. 13, no. 3, pp. 16-29, 1991.

[40] M. Sandelowski, "The problem of rigor in qualitative research," Advances in Nursing Science, vol. 8, no. 3, pp. 27-37, 1986.

[41] A. Kilroy, "Intra-urban spatial inequality: cities as "urban regions'”, World Development Report: Reshaping Economic Geography, 2007, http://siteresources.worldbank.org/INTWDR2009/Resources/4231006-1204741572978/Kilroy2.pdf.

[42] N. Kabeer, "Social exclusion, poverty and discrimination: towards an analytical framework," IDS Bulletin, vol. 31, no. 4, pp. 83-97, 2000.

[43] J. Hagedorn, "The business of drug dealing in Milwaukee," Wisconsin Policy Research Institute Report, vol. 11, no. 5, pp. 1-30, 1998.

[44] J. M. Hagedorn, People and Folks: Gangs, Crime, and the Underclass in a Rustbelt City, Lakeview Press, Chicago, Ill, USA, 2nd edition, 1998.

[45] A. B. Brenner, M. A. Zimmerman, J. A. Bauermeister, and C. H. Caldwell, "The physiological expression of living in disadvantaged neighborhoods for youth," Journal of Youth and Adolescence, vol. 42, no. 6, pp. 792-806, 2013.

[46] D. Finkelhor, R. K. Ormrod, and H. A. Turner, "Polyvictimization and trauma in a national longitudinal cohort," Development and Psychopathology, vol. 19, no. 1, pp. 149-166, 2007.

[47] S. Jain and A. K. Cohen, "Behavioral adaptation among youth exposed to community violence: a longitudinal multidisciplinary study of family, peer and neighborhood-level protective factors," Prevention Science, vol. 14, no. 6, pp. 606-617, 2013.

[48] L. O. Walker, B. S. Sterling, M. M. Hoke, and K. A. Dearden, "Applying the concept of positive deviance to public health data: a tool for reducing health disparities," Public Health Nursing, vol. 24, no. 6, pp. 571-576, 2007. 

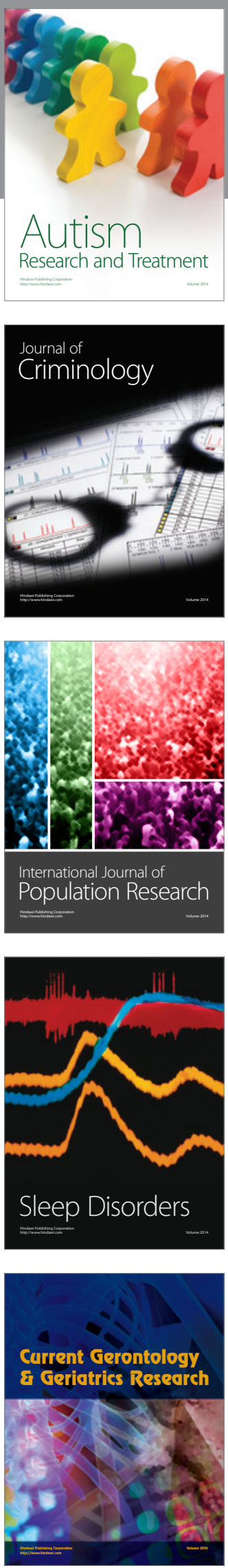
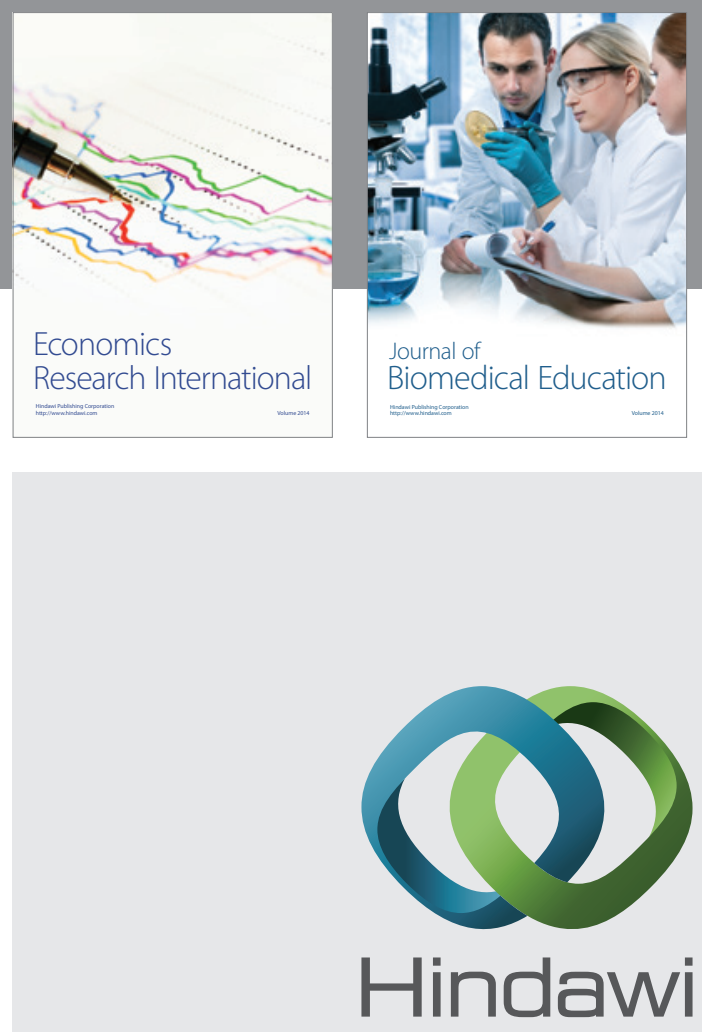

Submit your manuscripts at

http://www.hindawi.com
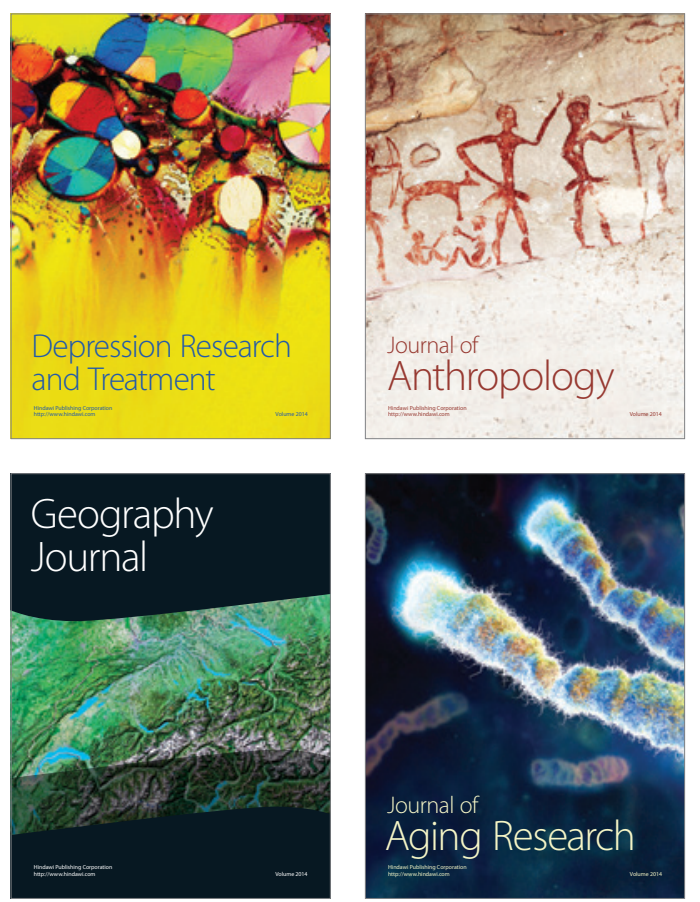
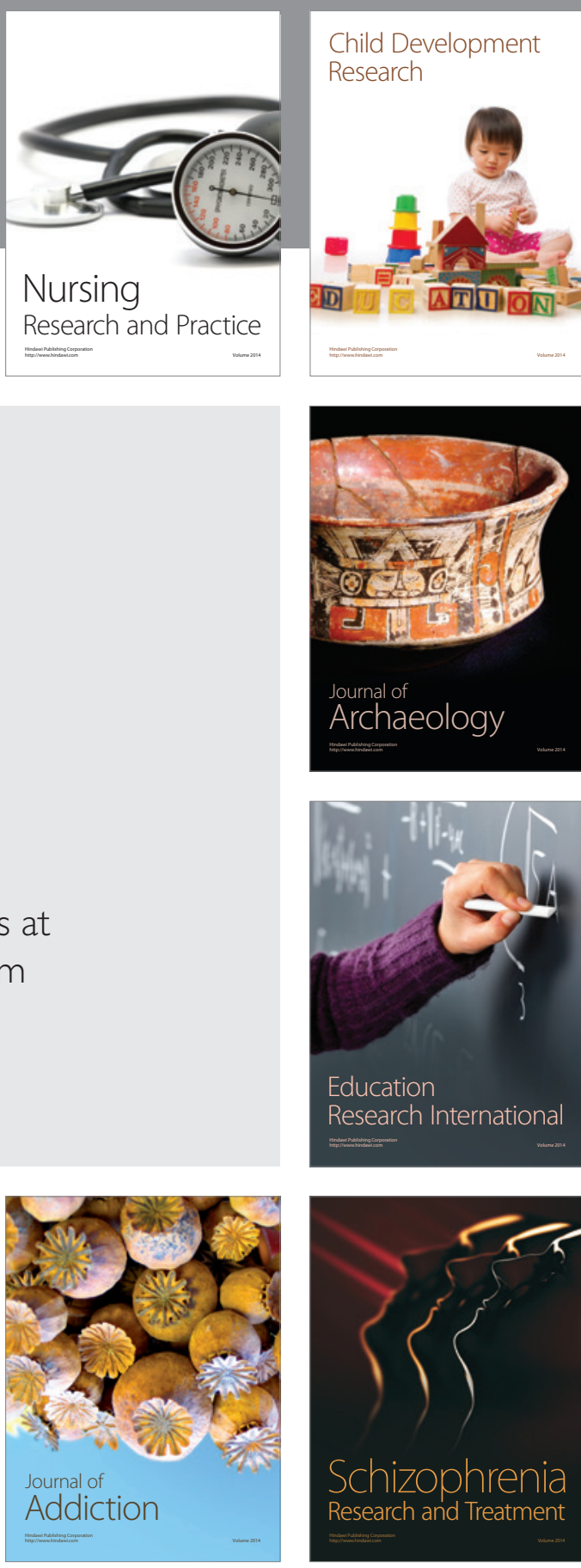

(D)
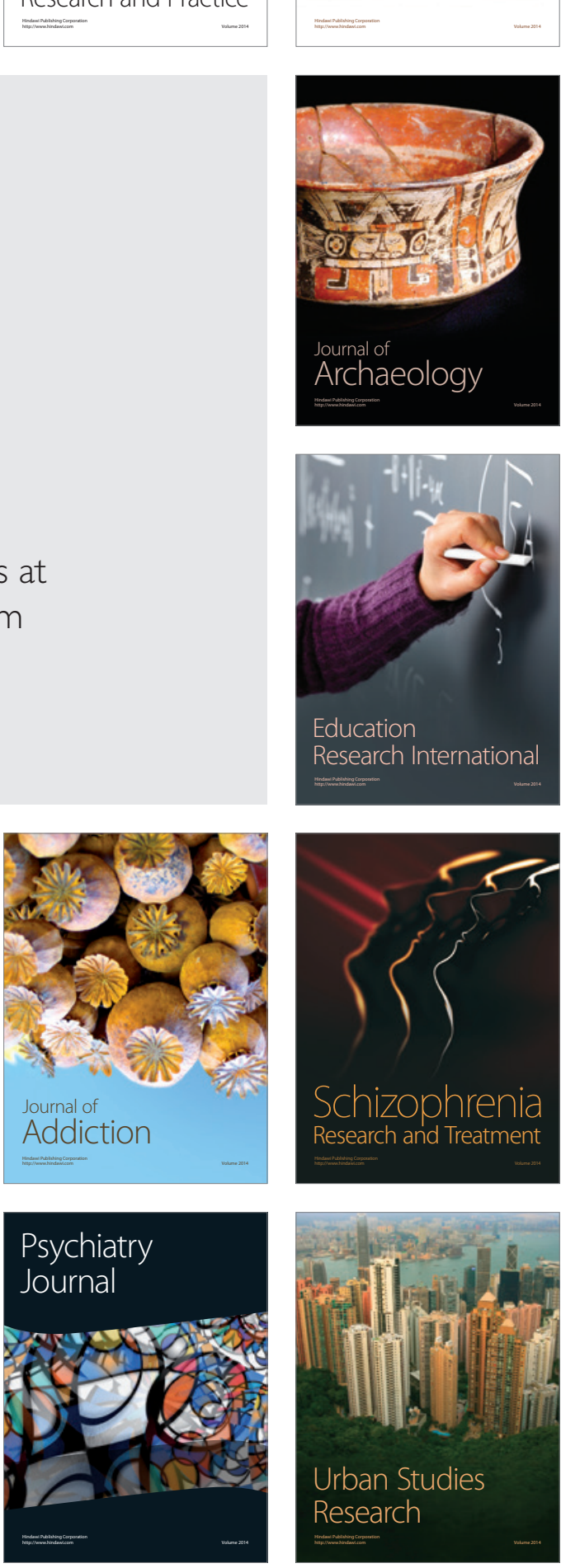